\title{
Pharmacology and clinical potential of vortioxetine in the treatment of major depressive disorder
}

This article was published in the following Dove Press journal:

Neuropsychiatric Disease and Treatment

I 5 July 2014

Number of times this article has been viewed

\author{
Enric Alvarez ${ }^{1,2}$ \\ Victor Perez ${ }^{4,2}$ \\ Francesc Artigas 3,2 \\ 'Department of Psychiatry, Hospital \\ de Sant Pau, Universitat Autonoma \\ de Barcelona, Institut de Recerca \\ Biomedica Sant Pau, Barcelona, Spain; \\ ${ }^{2}$ Ministry of Science and Innovation, \\ CIBERSAM, Madrid, Spain; ${ }^{3}$ nstitut \\ d'Investigacions Biomediques de \\ Barcelona, CSIC, Barcelona, Spain; \\ ${ }^{4}$ Institut de Neuropsiquiatria I \\ Adiccions, Universitat Autonoma \\ de Barcelona, Hospital del Mar, \\ Barcelona, Spain
}

\begin{abstract}
Vortioxetine is a new multimodal action antidepressant with two types of action: serotonin transporter (SERT) blockade and a strong affinity for several serotoninergic receptors. It is an antagonist of the 5-HT3 and 5-HT7 receptors, a partial agonist of 5-HT1B, and an agonist of 5-HT1A. Its combined action on SERT and four subtypes of serotoninergic receptors increases the extracellular concentration of serotonin, dopamine, and noradrenaline. Twelve clinical trials have been carried out, nine of which had positive results versus placebo. When active comparators were included in the study design, no significant differences were found except in one study in which the efficacy of vortioxetine was superior to the comparator (agomelatine) in depression resistant to selective serotonin reuptake inhibitors (SSRI)/serotonin-norepinephrine reuptake inhibitors (SNRI) treatment. Tolerability studies indicate that the drug does not cause any important problems on blood tests, vital signs, or on electrocardiography. The lack of weight gain and induction of metabolic syndrome and the lack of significant changes in the QTc are especially important. The incidence rate of sexual dysfunction is low and similar to placebo in various trials. Similarly, cognitive function remains intact with vortioxetine.
\end{abstract}

Keywords: depression, clinical trial, efficacy

\section{Introduction}

Major depressive disorder (MDD) is a disease that most commonly emerges in the third decade of life, with a high relapse rate and risk of chronicity. MDD is undoubtedly the maximum expression of human suffering and is the leading cause of death by suicide.

MDD is a common disease, with lifetime prevalence of around $13 \%$ and an incidence rate of $4 \% .{ }^{1}$ Females are twice as likely to suffer from major depression as males, and it is the main cause of suicide in both sexes. Approximately $15 \%$ of patients with depression die as a consequence of the illness ${ }^{2}$ and MDD accounts for at least $90 \%$ of all suicides. Suicide is currently the main cause of external death in all age groups in most European countries.

Sufficient evidence is available to support the idea that depression is a neuroprogressive disease, that is, the persistence of the clinical signs and symptoms implies structural changes in the neurons and neural tracts. ${ }^{3,4}$ Due to this neuroprogression, it is even more important to achieve the therapeutic objectives as quickly and effectively as possible.

The total cost of depression in Europe has been estimated at $€ 118$ billion, with the majority of this amount (61\%) due to indirect costs related to workplace productivity losses. ${ }^{5}$
Correspondence: Enric Alvarez

Department of Psychiatry, Hospital de Sant Pau, Av/Sant Antoni Mํㅡㄹ Claret 167, 08025 Barcelona, Spain

Tel +34935 53784 I

Fax +34935 537842

Email ealvarezm@santpau.cat 
According to the World Health Organization (WHO), depression is the second leading cause of disability expressed as disability-adjusted life years (DALYs), that is, years of healthy life lost - in patients aged 15-44 years. For 2020, the WHO estimates that depression will become the second leading cause of disability (DALYs) for all age groups. By 2030, depression is expected to become the leading cause of disability in industrialized countries. ${ }^{6}$

Despite the large number of antidepressants on the market, the treatment of depression still has numerous unmet needs, most of which are related to the efficacy and tolerability of the currently available drugs. Specifically, most antidepressants negatively affect sexual and cognitive function and can induce weight gain, and these effects often lead to therapeutic discontinuation. These treatment interruptions, in turn, increase the number of episodes and the risk of chronicity. Consequently, all of these factors taken together, increase the costs of depression at all levels (ie, personal, family, and economic).

The arrival of a new antidepressant on the market vortioxetine - that could partially mitigate these negative aspects will undoubtedly generate strong interest.

\section{Mechanism of action of vortioxetine}

Vortioxetine shows high affinity for the serotonin transporter (SERT) and several serotonin receptors. Thus, in vitro assay revealed that vortioxetine is a 5-hydroxytryptamine $(5-\mathrm{HT})_{3}, 5-\mathrm{HT}_{7}$, and $5-\mathrm{HT}_{1 \mathrm{D}}$ receptor antagonist, a $5-\mathrm{HT}_{1 \mathrm{~B}}$ receptor partial agonist, a $5-\mathrm{HT}_{1 \mathrm{~A}}$ receptor agonist, and SERT inhibitor. ${ }^{7-9}$ Binding affinities and functional activities of vortioxetine are similar in rat and human brain, with the exception of $5-\mathrm{HT}_{7}$ and $5-\mathrm{HT}_{1 \mathrm{~A}}$ receptors, which are approximately one order of magnitude weaker in rat brain. In agreement with its higher affinity for $5-\mathrm{HT}_{3}$ receptors and SERT, ex vivo autoradiography experiments show that vortioxetine occupies these sites at lower doses $(0.3-10 \mathrm{mg} / \mathrm{kg})$, whereas higher doses are required to occupy $5-\mathrm{HT}_{1 \mathrm{~B}}, 5-\mathrm{HT}_{1 \mathrm{~A}}$, and $5-\mathrm{HT}_{7}$ receptors.

In vivo microdialysis studies showed that vortioxetine increases the extracellular concentration of serotonin $(5-\mathrm{HT})$ more than the serotonin selective reuptake inhibitors (SSRI) in depression-related areas, such as the medial prefrontal cortex (mPFC) and the hippocampus. ${ }^{8,10}$ Vortioxetine also increases the extracellular concentration of noradrenaline (NA), dopamine (DA), acetylcholine (Ach), and histamine (HA) in rat brain. ${ }^{8}, 10$ The greater elevations of extracellular 5 -HT evoked by vortioxetine likely result from its multimodal mechanism of action. Indeed, various 5-HT receptors for which vortioxetine shows high affinity have been implicated in the mechanism of action of antidepressant drugs, ${ }^{11}$ and several of them participate in negative feedback mechanisms that limit the action of SSRI. ${ }^{12,13}$ In particular, the blockade of 5- $\mathrm{HT}_{3}$ receptors by vortioxetine may be involved in these neurochemical effects, since the $5-\mathrm{HT}_{3}$ receptor antagonist ondansetron augments the increase in extracellular 5-HT produced by SSRI in $\mathrm{mPFC}$ and the hippocampus. ${ }^{8}$ Likewise, vortioxetine (but not escitalopram) increased the discharge rate of pyramidal neurons in rat $\mathrm{mPFC}$, an effect that depends on 5 - $\mathrm{HT}_{3}$ receptor blockade. ${ }^{14}$

Vortioxetine's actions at 5-HT receptors may be involved in the elevations of extracellular DA, NA, Ach, and HA evoked by the drug in rat brains, ${ }^{8}$ given the multiple and mutual interactions between these neurotransmitter systems. Likewise, this mechanism may also explain the greater elevations in extracellular 5-HT produced by vortioxetine in comparison with the SSRI at a given occupancy of SERT. ${ }^{9}$

Vortioxetine shows good bioavailability after oral dosing (75\%) with a $t_{\max }$ of 7-8 hours and a half-life $\left(t_{1 / 2}\right)$ of 57 hours, and achievement of stable plasma concentrations in $<2$ weeks. The rate of binding to plasma proteins was $96 \%$. It is metabolized by several hepatic P-450 isoenzymes such as CYP2D6, CYP3A4/5, CYP2C9, CYP2C19, CYP2A6, CYP2C8, and CYP2B6. ${ }^{15}$ It does not inhibit nor activate any of them, showing linear kinetics. Its main metabolite is inactive.

\section{Efficacy of vortioxetine}

Twelve clinical trials have been carried out to assess the short-term efficacy (6 or 8 weeks) of vortioxetine (see Table 1). ${ }^{16-27}$ Two long-term trials have been conducted to assess its efficacy in preventing relapses.

Of the 12 efficacy trials for new episodes of depression, eight were positive for vortioxetine versus placebo, ${ }^{19-21,23-27}$ while three studies (two of which were carried out only in the US) showed no significant differences versus placebo, ${ }^{16,18,22}$ with one failed study. ${ }^{17}$ In one of the negative trials, Jain et a ${ }^{16}$ includes a detailed discussion of most of the factors that can affect placebo response.

Six of the positive studies achieved positive results in the treatment arms that received 5-20 mg/day. In contrast, in two other positive studies, vortioxetine was superior to placebo only in the highest dose arms ( $20 \mathrm{mg} /$ day) but not at 10 or $15 \mathrm{mg} /$ day. One of the trials ${ }^{17}$ was considered to be "failed" because neither vortioxetine nor the active comparator (duloxetine) were superior to placebo. Another trial ${ }^{18}$ was clearly negative for vortioxetine because the results were 
positive for the active comparator (duloxetine). However, it is important to note that one of the inclusion criteria required that subjects not be resistant to duloxetine, and this requirement could have biased the results. In the other two negative trials, vortioxetine was compared only to placebo and the lack of an active comparator makes the results of those trials more uncertain.

Patients who respond to vortioxetine typically do so after approximately 2 weeks of treatment, with the maximum response seen near the fourth week. However, McIntyre et $\mathrm{al}^{19}$ observed significant differences versus placebo in the first week at doses of $20 \mathrm{mg} /$ day, whereas these differences did not emerge until the second week in the $10 \mathrm{mg} /$ day arm.

Table 1 shows the efficacy data and other relevant details of these 12 trials. Six of these 12 studies have been published as articles in various medical journals while the remaining six studies have not yet been published, but were presented as posters in relevant congresses. All these trials involve patients who presented an episode of major depression (Diagnostic and Statistical Manual of Mental Disorders [DSM-IV] criteria) of at least 3 months' duration without any history of treatment resistance. The only exception was the direct comparison trial of vortioxetine and agomelatine, conducted in patients who showed no or inadequate response to SSRI/ serotonin-norepinephrine reuptake inhibitors (SNRI) for at least 6 weeks at maximal doses. ${ }^{20}$

These 12 studies were conducted in patient populations ranging 18-75 years, with a mean age of 42-48 years. Females made up the majority of patients $(62.5 \%-78 \%)$ in all the samples. Five of the studies were performed only in the US, ${ }^{16,18,21-23}$ while the remaining seven were conducted in numerous other countries. ${ }^{17,19,20,24-27}$

The main variable assessed in all the studies was the change in the Montgomery-Åsberg Depression Rating Scale (MADRS) or in the Hamilton Depression Rating Scale (HAMD). Baseline scores on the MADRS ranged from 29 to 34 depending on the inclusion criteria of the particular study, which varied slightly. The percentage of patients in each trial who completed the full study ranged from $74 \%-90 \%$. Two trials involved only ambulatory patients while another two included both ambulatory and inpatients (without differential analysis); in the remaining studies, no details regarding this aspect have been provided. There were no significant differences between treatment groups in any of the trials in terms of demographic or clinical variables that could have biased the results.

All the trials were performed on an intention-to-treat basis with the last observation carried forward (LOCF) but according to the full analysis set (FAS) version, which includes all patients who have been assessed at least once after randomization.

Two medium/long-term efficacy studies of vortioxetine have been performed. One of these was a randomized doubleblind controlled clinical trial designed to assess the ability of vortioxetine to prevent new relapses of depression. ${ }^{28}$ No less interesting is the open-label efficacy extension study carried out by Baldwin et $\mathrm{al}^{29}$ under conditions considered closer to "real life". Although this was a tolerability study, the complementary efficacy data are relevant.

The first of these long-term trials ${ }^{28}$ was conducted in a sample of 639 patients recruited in 17 countries. The design consisted of a 12-week period during which patients were treated on an open-label basis with flexible doses of vortioxetine (5-10 mg/day); after the eighth week, the dose was fixed for the remainder of the study period. Patients in remission (MADRS $\leq 10$ ) were randomized to receive double-blind treatment with placebo or with the same dose level of vortioxetine that was needed to achieve remission. Final assessment was performed when the last patient recruited had finalized the required 24 weeks of follow-up (the first patients included in the trial were followed for 64 weeks). A significant difference was found in the mean relapse rate between patients in the placebo group and patients who continued with the active drug ( $26 \%$ versus [vs] $13 \%, P=0.0035)$, thus confirming the ability of vortioxetine to retain its therapeutic activity.

In the second long-term trial, ${ }^{29}$ all patients received $5 \mathrm{mg}$ /day during the first week; after this time, the openlabel design permitted the researchers to administer flexible doses (between 2.5 and $10 \mathrm{mg} /$ day) at their discretion. This approach approximates the real conditions of antidepressant treatment, except that the range of doses was perhaps smaller than it would have been in real conditions. The treatment period was 12 months. Although the main outcomes of that study are related to tolerability, the treatment "effectiveness" outcomes are also of interest: the MADRS decreased by a mean of 8 points, the percentage of responders increased from $63 \%$ to $94 \%$, and remissions (MADRS $<10$ ) rose from $42 \%$ to $83 \%$. Moreover, among the patients in remission at the start of the study, the relapse rate was only $9.7 \%$.

Few clinical trials have been performed to assess efficacy in switching from one antidepressant to another in resistant depression. For this reason, the trial carried out by Häggström et $\mathrm{a}^{20}$ is particularly noteworthy. Their study was conducted in patients who did not respond (or responded inadequately) to SSRI or SNRI monotherapy drugs (citalopram, escitalopram, paroxetine, sertraline, duloxetine, and 


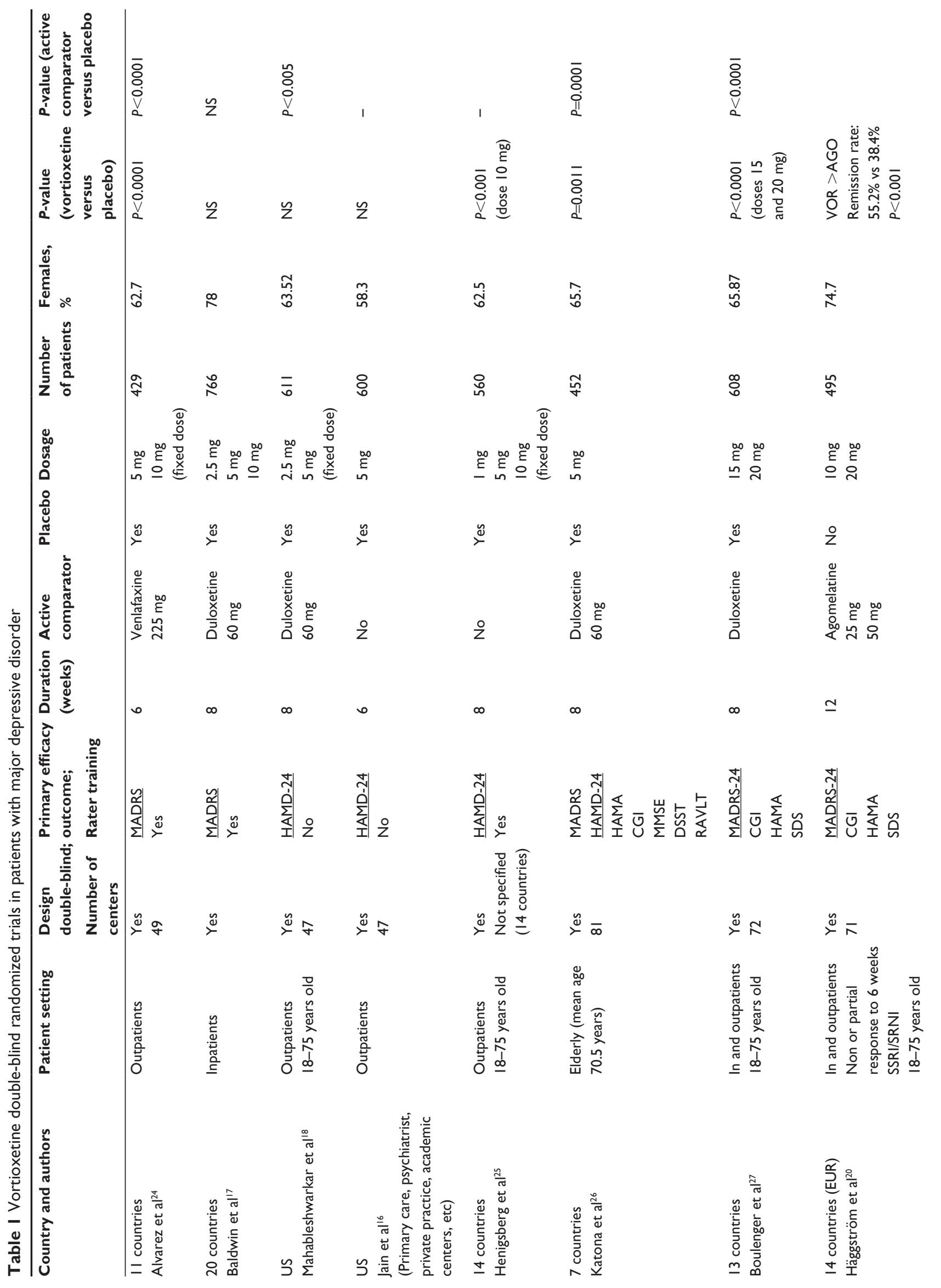




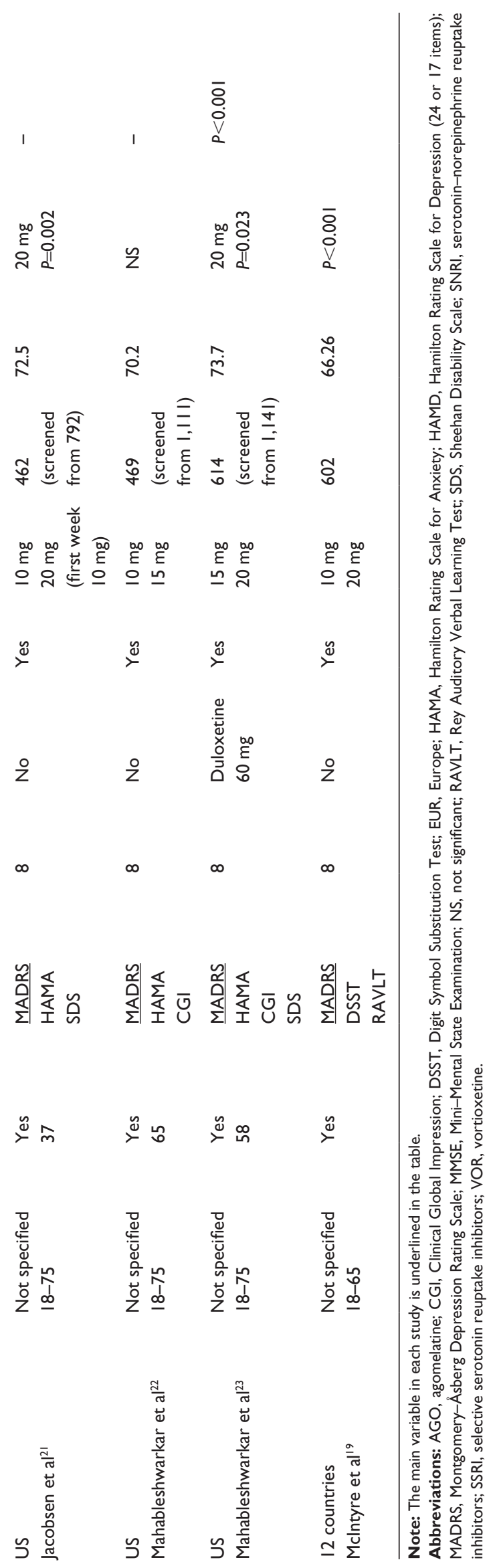

venlafaxine) administered at appropriate doses (up to the maximum dose allowed) and for sufficient periods of time (at least 6 weeks). All patients in the study were considered candidates for a monotherapeutic drug-switching strategy. Given the resistant nature of these patients' depression, this trial could be considered a "paradigm shift" in the pharmacological treatment of depression, as the patients were randomized to receive either: a) agomelatine, a melatoninergic agonist that induces an increase in the release of NA and $\mathrm{DA}^{30}$ or b) vortioxetine, which, in addition to antagonizing SERT, possesses the multimodal capacities described previously, which promote the release of catecholamines in some regions of the brain. ${ }^{10}$ The prescribed doses of both drugs assured maximum therapeutic activity: $25-50 \mathrm{mg} /$ day of agomelatine versus $10-20 \mathrm{mg} /$ day of vortioxetine. After 12 weeks, patients in both groups had improved significantly, with a mean decrease of 16.5 points on the MADRS for the vortioxetine group versus 14.4 points for agomelatine $(P<0.01)$. Vortioxetine was shown to be significantly better in therapeutic response (50\% improvement in MADRS; $P<0.01)$ and in remissions (MADRS $\leq 10 ; P<0.001$ ). Despite the theoretical limitation of this study (ie, lack of a placebo arm), this was a non-experimental patient population recruited from daily clinical practice after having received conventional treatment. As a result, this population was much closer to "real world" patients.

\section{Vortioxetine tolerability}

The safety data from the 12 short-term efficacy studies are shown in Table 2. In general, tolerability was excellent. The most common adverse events (AEs), with an incidence rate $>5 \%$, were nausea, vomiting, constipation, and headaches. In some trials, vortioxetine resulted in an incidence rate for these AEs that was similar to that for placebo and better than the active comparators. However, the incidence of AEs for vortioxetine was higher than for placebo only at the highest ( $20 \mathrm{mg} /$ day) dose arms: Boulenger et $\mathrm{al}^{27} 66.2 \%$ versus 50.6\%; Jacobsen et $\mathrm{al}^{21} 68.7 \%$ versus $62.4 \%$; and Mahableshwarkar et $\mathrm{al}^{23} 81.2 \%$ versus $70.4 \%$.

In most of the studies, at doses of $10 \mathrm{mg}$ or more, AE-related withdrawals were greater in the vortioxetine arms versus placebo and lower than the active comparator, except in the Mahableshwarkar et al study ${ }^{23}$ However, at doses $<10 \mathrm{mg}$, vortioxetine showed no differences versus placebo in terms of withdrawals. Detailed data on withdrawals due to AEs are shown in Table 3.

No relevant differences between vortioxetine and placebo have been observed in terms of vital signs, including 


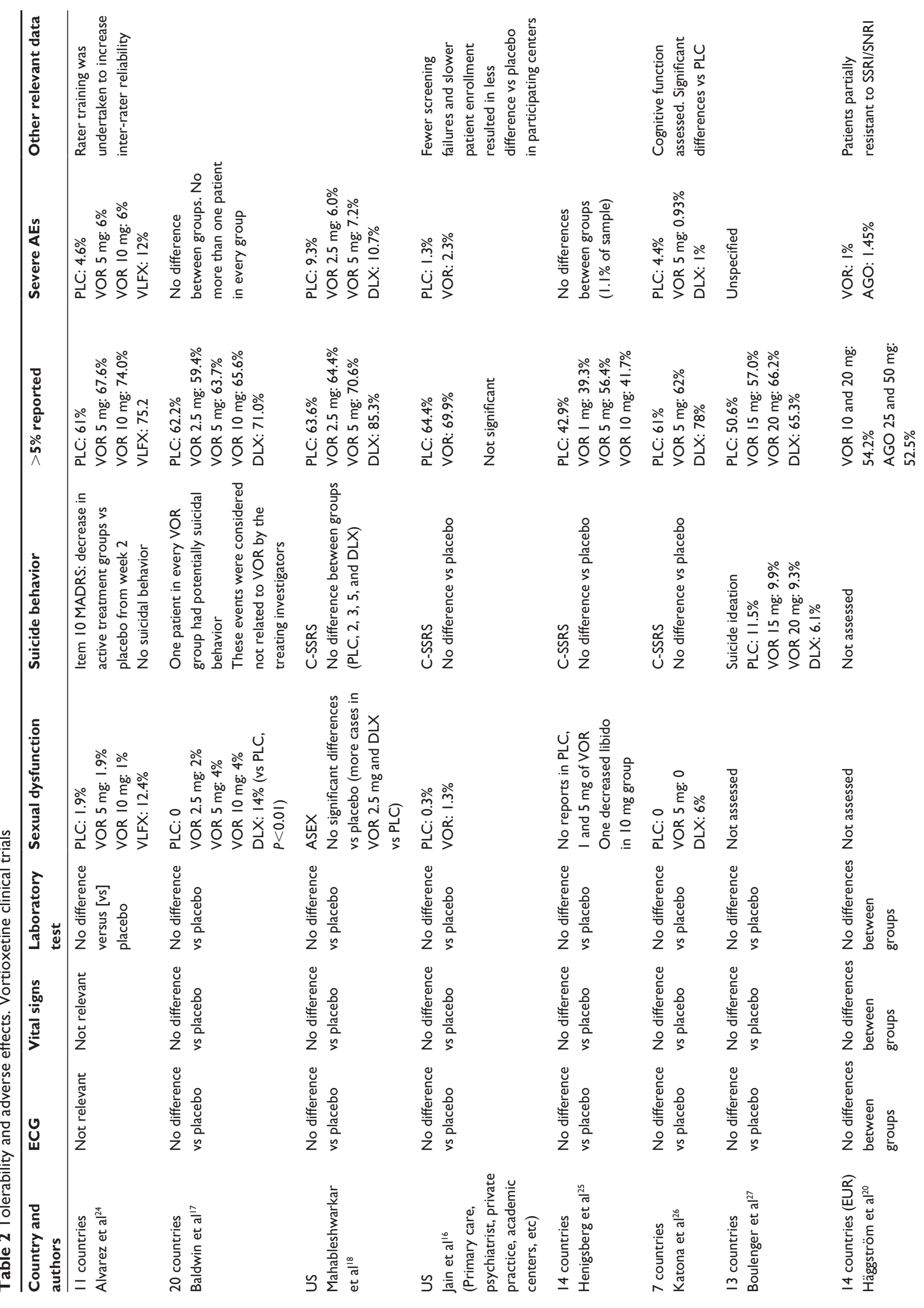




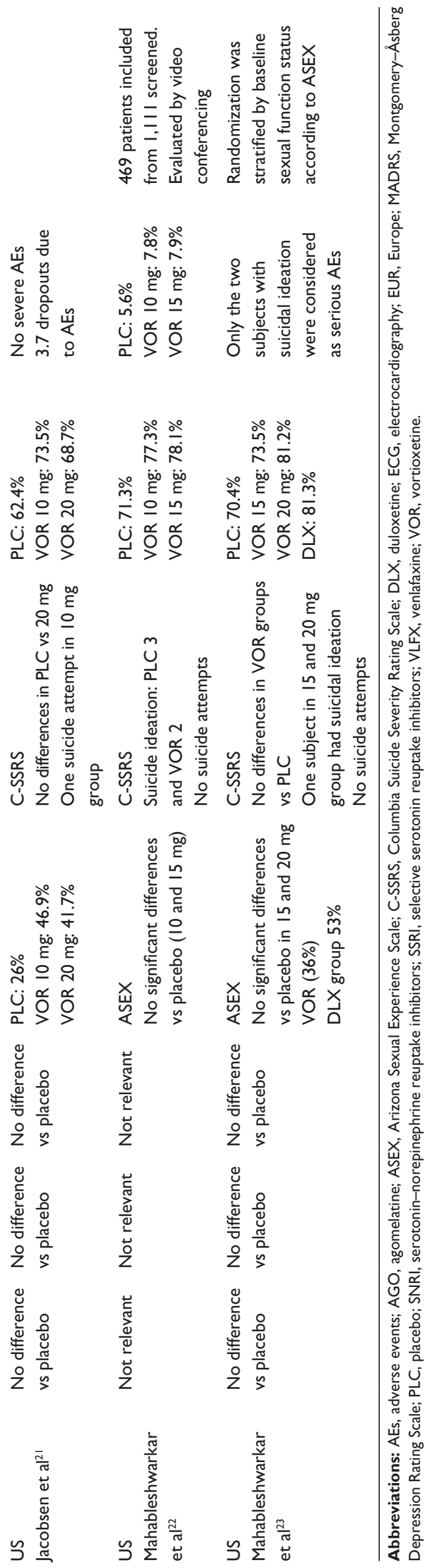

arterial blood pressure and heart rate. Similarly, no alterations in any cardiac parameters - including the QT segments - have been seen on electrocardiographic examinations, with no significant differences between placebo and vortioxetine.

One particularly interesting characteristic of vortioxetine is that it appears to have no effect on weight, in contrast to other antidepressants in which the association between induction of weight gain and the presence of other metabolic alterations has been established. This is important given that weight gain and sexual dysfunction are the main AEs responsible for poor therapeutic adherence.

\section{Sexual dysfunction}

Deterioration in sexual function is the $\mathrm{AE}$ that most concerns both patients and clinicians alike. A recent meta-analysis on this topic ${ }^{31}$ assessed the incidence of emerging sexual dysfunction reported in studies of antidepressant medications. That meta-analysis found that only antidepressant drugs without serotoninergic activity were able to maintain low rates of sexual dysfunction similar to placebo. However, to achieve remission, most patients require an antidepressant with serotoninergic activity, which is why SSRI/SNRI are used in most monotherapy treatments. In contrast, catecholaminergic drugs are used mainly in combined therapies, as occurs with bupropion or mirtazapine.

The proportion of patients who develop treatment-related emerging sexual dysfunction will depend on the specific medication. A few notable examples include sertraline (80\% of patients), venlafaxine (79.8\%), duloxetine (41\%), and escitalopram (37\%). ${ }^{31}$

Clinical trials of vortioxetine performed in acute patients indicate that the percentage of patients who develop emerging sexual dysfunction is considerably lower for this drug than for other antidepressants, even though vortioxetine is essentially a serotoninergic agonist. In the studies that have reported spontaneous sexual dysfunction, the proportion of patients with sexual dysfunction was the same or close to placebo and significantly lower than that for the active comparators venlafaxine ${ }^{24}$ and duloxetine. ${ }^{17,26}$ However, it should be noted that when a specific instrument, such as the Arizona Sexual Experience Scale (ASEX) was used, the percentage of sexual dysfunction increased in all groups treated with $20 \mathrm{mg} /$ day of vortioxetine. However, this increase was only significant versus placebo in one study. ${ }^{21}$

The data from the two long-term studies of vortioxetine merit special attention, especially considering the relevance of sexual dysfunction in the general population: premature ejaculation and erectile dysfunction in $14 \%$ and $10 \%$ of 
Table 3 Withdrawal due to AEs in VOR double-blind, randomized trials in patients with major depressive disorder

\begin{tabular}{|c|c|c|c|c|c|c|c|c|}
\hline Country and authors & Placebo & $\begin{array}{l}\mathrm{I}-2.5 \mathrm{mg} / \mathrm{day} \\
\text { of VOR }\end{array}$ & $\begin{array}{l}5 \mathrm{mg} / \mathrm{day} \\
\text { of VOR }\end{array}$ & $\begin{array}{l}\text { I0-15 mg/day } \\
\text { of VOR }\end{array}$ & $\begin{array}{l}20 \mathrm{mg} / \text { day } \\
\text { of VOR }\end{array}$ & $\begin{array}{l}60 \mathrm{mg} / \text { day } \\
\text { of DLX }\end{array}$ & $\begin{array}{l}225 \mathrm{mg} / \text { day } \\
\text { of VLFX }\end{array}$ & $\begin{array}{l}25-50 \mathrm{mg} / \mathrm{day} \\
\text { of AGO }\end{array}$ \\
\hline II countries & 3.8 & & 2.7 & 7 & & & 14.2 & \\
\hline \multicolumn{9}{|l|}{ Alvarez et $\mathrm{al}^{24}$} \\
\hline 20 countries & 8 & 6 & 11 & 9 & & 12 & & \\
\hline \multicolumn{9}{|l|}{ Baldwin et $\mathrm{al}^{17}$} \\
\hline US & 4.57 & 4.57 & 7.84 & & & 11.18 & & \\
\hline \multicolumn{9}{|l|}{ Mahableshwarkar et al ${ }^{18}$} \\
\hline US & 3.66 & & 3 & & & & & \\
\hline \multicolumn{9}{|l|}{ Jain et $\mathrm{al}^{16}$} \\
\hline \multicolumn{9}{|l|}{ (Primary care, psychiatrist, } \\
\hline \multicolumn{9}{|l|}{ private practice, academic } \\
\hline \multicolumn{9}{|l|}{ centers, etc) } \\
\hline 14 countries & $\mathrm{I} .42$ & 2.14 & 0.71 & 3.57 & & & & \\
\hline \multicolumn{9}{|l|}{ Henigsberg et $\mathrm{a}^{25}$} \\
\hline 7 countries & 4.13 & & 6.41 & & & 9.93 & & \\
\hline \multicolumn{9}{|l|}{ Katona et $\mathrm{al}^{26}$} \\
\hline 13 countries & 3.75 & & & 6.71 & 11.2 & 4.79 & & \\
\hline \multicolumn{9}{|l|}{ Boulenger et $\mathrm{al}^{27}$} \\
\hline I4 countries (EUR) & & & & & 5.9 & & & 9.5 \\
\hline \multicolumn{9}{|l|}{ Häggström et $\mathrm{al}^{20}$} \\
\hline US & 1.27 & & & 5.81 & 4.66 & & & \\
\hline \multicolumn{9}{|l|}{ Jacobsen et $\mathrm{a}^{21}$} \\
\hline US & 3.75 & & & $5.09 / 7.89$ & & & & \\
\hline \multicolumn{9}{|l|}{ Mahableshwarkar et $\mathrm{al}^{22}$} \\
\hline US & 2.48 & & & 9.52 & 9 & 6.57 & & \\
\hline \multicolumn{9}{|l|}{ Mahableshwarkar et $\mathrm{a}^{23}$} \\
\hline 12 countries & 4.1 & & & 3.6 & 5.3 & & & \\
\hline Mclntyre et al ${ }^{19}$ & & & & & & & & \\
\hline
\end{tabular}

Abbreviations: AEs, adverse effects; AGO, agomelatine; DLX, duloxetine; EUR, Europe; VLFX, venlafaxine; VOR, vortioxetine.

men, respectively, and hypoactive sexual desire disorder in $16 \%-46 \%$ of premenopausal women. ${ }^{32}$

In the randomized, double-blind, long-term efficacy study, ${ }^{28}$ sexual dysfunction was observed in two subjects in the placebo group (erectile dysfunction and anorgasmia, respectively) and three in the vortioxetine $(5-10 \mathrm{mg} /$ day) group (erectile dysfunction, libido reduction, and anorgasmia, respectively) during the controlled phase of the study. Additionally, it is worth pointing out that four patients became pregnant during this treatment period and of those patients, three elected to interrupt the pregnancy while one gave birth to a healthy boy.

In the open-label extension study, ${ }^{29}$ six patients (out of a total of 336) - four men and two women - developed emerging sexual dysfunction. Four of these patients experienced reduced sexual impulse: two experienced a total loss of sexual drive while the remaining two developed, respectively, erectile dysfunction and anorgasmia. These cases of sexual dysfunction are understood to be "emergent", that is, arising after treatment initiation, without regard to prior sexual satisfaction status.

Available data on the pharmacological mechanism of action that could explain the scant induction of sexual dysfunction by vortioxetine compared to other antidepressants are scarce. Vortioxetine, in contrast to SSRI/SNRI, has an affinity for various serotoninergic receptors as discussed earlier. However, we do not know what role if any these receptors have in modulating sexual impulse. However, one study that could shed light on this question is the one carried out by Amstislavskaya and Popova, ${ }^{33}$ who showed that plasma testosterone levels in male rats treated with SSRI and in proximity to a female recovered when the rats were treated with a potent antagonist of the $5-\mathrm{HT}_{3}$ receptor, such as ondansetron. Although this is only a scientific speculation, the role of this receptor and of other receptors for which vortioxetine has an affinity could present an interesting line of research for further investigation into the relationship between increased serotoninergic activity and decreased sexual impulse.

\section{Cognitive function}

Since tricyclic antidepressants were excluded as first-line treatments for depression, the devastating effects on cognitive function that these drugs can cause in older or elderly adult patients have practically disappeared from daily 
clinical practice. However, it is not unusual for patients treated with SSRI/SNRI to complain about impaired cognitive performance (especially older people), which is probably due to excessive neuromodulation of the release of catecholamines, which occurs with increased 5-HT function.

The excellent study by Katona et $\mathrm{al}^{26}$ on the efficacy of vortioxetine (with duloxetine as the active comparator) in the treatment of depression in the elderly population appropriately included an assessment of cognitive function. The fact that age is a determining factor in "natural cognitive decline" as well as in drug-induced cognitive dysfunction implies that it is reasonable to extrapolate the results to younger populations. In their study, the inclusion criteria excluded patients with a mini-mental state examination (MMSE) score of $<24$ points, thus eliminating all cases with neurodegenerative disease. To evaluate the effects of treatment on cognitive function, subjects underwent an examination at baseline and then at the end of the study. Verbal learning, memory, and processing speed were all assessed using the following tests (administered in this order): the Rey Auditory Verbal Learning Test (RAVLT) and the digit symbol substitution test (DSST).

Patients randomized to the active drug showed significantly greater improvement versus placebo and versus duloxetine. The effect size compared to placebo was assessed via path analysis, with the results showing that vortioxetine had an $83 \%$ direct effect on the DSST score versus $26 \%$ for duloxetine. Similarly, in the RAVLT, vortioxetine had an effect size of $71 \%$ versus $65 \%$ and in re-memorization, $72 \%$ versus $66 \%$.

These data suggest that vortioxetine does not induce cognitive problems but may actually improve the baseline condition. This makes this drug especially recommendable in older patients and in patients who complain of cognitive impairment during treatment.

\section{Discussion}

The proportion of negative clinical trials for a new drug varies greatly. In some instances, up to $50 \%$ of trials were negative in antidepressants that ultimately achieved final regulatory approval. ${ }^{34}$ In the case of vortioxetine, with the exception of the "failed" study by Baldwin et al ${ }^{17}$ only three trials failed to show significant differences between the active drug and placebo. In one of those trials, ${ }^{16}$ the authors discuss in detail the possible reasons that might explain the negative results of a clinical trial and they analyze their own results in this context. Among the most important reasons they give is that researchers might inadvertently "inflate" the baseline severity of patients included in the study as a consequence of the inclusion criteria, with subsequent overestimation of the therapeutic response. ${ }^{35}$ In the same study, a "post-hoc" analysis showed that this exaggeration of baseline severity likely occurred in the recruitment centers with the fastest enrollment or in those with fewer screen failures. The expectations of subjects who have previously participated in other similar clinical trials could also have an effect on therapeutic response. ${ }^{36}$

The three negative vortioxetine studies were carried out entirely in the US (see Table 1). The well-known professionalization of the evaluators and patients in clinical trials that are conducted in the US supports the arguments given above with regards to inflation of the response to placebo. This is an issue that the regulatory agencies (US Food and Drug Administration and European Medicines Agency) need to address as soon as possible. An impeccable study design with follow-up according to "Good Practices" is not enough. The factors and motivations surrounding sample selection are important aspects that must be considered.

Notwithstanding those three negative studies, it is important to note that vortioxetine has been proven superior to placebo and/or active comparators in eight other studies (see Table 1). However, for reasons that have already been discussed in the present review, even though some of the studies found significant differences versus placebo, these differences do not necessarily imply a large difference between the active drug and placebo. The efficacy/registration studies of a new drug may not show an important size effect. To gain a better understanding of these differences, we recommend that readers consult the excellent systematic review of vortioxetine carried out by Citrome, in which these differences are discussed in depth. ${ }^{37}$

Vortioxetine is undoubtedly a good first-line therapeutic option in patients with depression. Vortioxetine also presents some remarkable differences when compared to the drugs currently on the market, and these characteristics indicate that it could also be used as a second-line therapy when the results of first-line treatments are unsatisfactory. Clinicians may wish to consider switching from the treatment in course to vortioxetine when one of the three conditions following arise, even if the current treatment is considered successful in terms of therapeutic response.

First, in cases in which the patient complains about cognitive function after the depression has improved: the decrease in catecholamine release triggered by the increase of serotoninergic activity during treatment with SSRI explains why attention and cognitive performance are lower than expected. The two studies that assessed the influence of vortioxetine on cognitive function have shown that it preserves 
cognitive function in elderly patients ${ }^{26}$ and even improves it in nonresponders. McIntyre et al very recently reported, at the American College of Neuropsychopharmacology (ACNP), the results of a clinical trial that supports the positive effect of vortioxetine on cognitive function in addition to its efficacy versus placebo. ${ }^{19}$ In their study (no active comparator), the authors showed improved cognition even in patients who did not meet the criteria for therapeutic response.

Secondly, in patients who experience a treatment-related decline in sexual functioning, vortioxetine may offer an alternative. Deterioration in preexisting sexual function is the AE that causes the greatest concern among both patients and clinicians. In patients who show an adequate therapeutic response to SSRI/SNRI but in whom treatment compliance is compromised by the presence of emerging sexual dysfunction, the switch to vortioxetine can improve the situation. In this regard, it is important to keep in mind that only the $20 \mathrm{mg} /$ day dose of vortioxetine is associated with greater sexual dysfunction than placebo. The frequency of emerging sexual dysfunction has been widely discussed by other authors. ${ }^{31}$

Finally, in patients with an inadequate therapeutic response - even at maximum dosage - switching to vortioxetine may improve the response. The scant information available about the value of switching to another antidepressant gives special relevance to the clinical trial that directly compared vortioxetine to agomelatine. ${ }^{20}$ Maintaining a patient in monotherapy is a good alternative to the usual strategy of combined treatments with other antidepressants or to the addition of lithium - common strategies in cases with poor therapeutic response - but these strategies can increase the number of AEs. It is particularly relevant that the sample selection in that trial was much closer to "real world" patients than in the other studies of vortioxetine, which thus compensates for the lack of a placebo arm.

The multimodal mechanism of action of vortioxetine may be involved in the procognitive activity and low incidence of sexual side effects observed in Phase II/III clinical trials. Further studies are required to confirm these observations and to examine the exact mechanisms involved. Overall, the pharmacological properties of vortioxetine differ from those of existing antidepressant drugs. However, only its extensive use in large patient populations will allow us to assess whether the distinct preclinical properties of vortioxetine translate into a clinical profile that differs from that of SSRI and SNRI.

\section{Acknowledgments}

The study was supported by the Instituto de Salud Carlos III, Centro de Investigación Biomédica en Red de Salud Mental,
CIBERSAM, as well as grant SAF 2012-35183 to FA (Spanish Ministry of Economy and Competitiveness, co-financed by European Regional Development Fund, ERDF).

The authors would like to thank Bradley Londres for his contribution in preparing the manuscript.

\section{Disclosure}

Dr Enric Alvarez has received consulting and educational honoraria from several pharmaceutical companies, including Eli Lilly, Sanofi-Aventis, Lundbeck, and Pfizer, and has participated as the main local investigator in clinical trials from Eli Lilly, Bristol-Myers, and Sanofi-Aventis and also as the national coordinator of clinical trials from Servier and Lundbeck.

Dr Victor Perez declares having received educational honoraria from: Sanofi-Aventis, Lundbeck, Pfizer, AstraZeneca, and Eli Lilly.

Dr Francesc Artigas has received lecture fees from Eli Lilly and Lundbeck on the mechanism of action of antidepressant drugs and consultation fees from Lundbeck.

The authors declare no financial interests or potential conflicts of interest related directly or indirectly to this work.

\section{References}

1. Alonso J, Angermeyer MC, Bernert S, et al; ESEMeD/MHEDEA 2000 Investigators; European Study of the Epidemiology of Mental Disorders (ESEMeD) Project. Prevalence of mental disorders in Europe: results from the European Study of the Epidemiology of Mental Disorders (ESEMeD) project. Acta Psychiatr Scand Suppl. 2004;420:21-27.

2. Guze SB, Robins E. Suicide and primary affective disorders. $B r J$ Psychiatry. 1970;117(539):437-438.

3. de Diego-Adeliño J, Pires P, Gómez-Ansón B, et al. Microstructural white-matter abnormalities associated with treatment resistance, severity and duration of illness in major depression. Psychol Med. Epub 2013 Aug 21.

4. Serra-Blasco M, Portella MJ, Gómez-Ansón B, et al. Effects of illness duration and treatment resistance on grey matter abnormalities in major depression. Br J Psychiatry. 2013;202:434-440.

5. Valladares A, Dilla T, Sacristán JA. [Depression: a social mortgage. Latest advances in knowledge of the cost of the disease]. Actas Esp Psiquiatr. 2009;37(1):49-53. Spanish.

6. Mathers CD, Loncar D. Projections of global mortality and burden of disease from 2002 to 2030. PLoS Med. 2006;3(11):e442.

7. Bang-Andersen B, Ruhland T, Jørgensen M, et al. Discovery of 1-[2(2,4-dimethylphenylsulfanyl) phenyl]piperazine (Lu AA21004): a novel multimodal compound for the treatment of major depressive disorder. J Med Chem. 2011;54(9):3206-3221.

8. Mørk A, Pehrson A, Brennum LT, et al. Pharmacological effects of Lu AA21004: a novel multimodal compound for the treatment of major depressive disorder. J Pharmacol Exp Ther. 2012;340(3):666-675.

9. Areberg J, Luntang-Jensen M, Søgaard B, Nilausen DØ. Occupancy of the serotonin transporter after administration of Lu AA21004 and its relation to plasma concentration in healthy subjects. Basic Clin Pharmacol Toxicol. 2012;110(4):401-404.

10. Pehrson AL, Cremers T, Bétry C, et al. Lu AA21004, a novel multimodal antidepressant, produces regionally selective increases of multiple neurotransmitters - a rat microdialysis and electrophysiology study. Eur Neuropsychopharmacol. 2013;23(2):133-145. 
11. Artigas F. Serotonin receptors involved in antidepressant effects. Pharmacol Ther. 2013;137(1):119-131.

12. Artigas F, Perez V, Alvarez E. Pindolol induces a rapid improvement of depressed patients treated with serotonin reuptake inhibitors. Arch Gen Psychiatry. 1994;51(3):248-251.

13. Artigas F, Romero L, de Montigny C, Blier P. Acceleration of the effect of selected antidepressant drugs in major depression by 5-HT1A antagonists. Trends Neurosci. 1996;19(9):378-383.

14. Riga MS, Celada P, Sanchez C, Artigas F. Role of 5-HT3 receptors in the mechanism of action of the investigational antidepressant vortioxetine. Eur Neuropsychopharm. 2013;Suppl 2:S393-S394.

15. Hvenegaard MG, Bang-Andersen B, Pedersen H, Jørgensen M, Püschl A, Dalgaard L. Identification of the cytochrome P450 and other enzymes involved in the in vitro oxidative metabolism of a novel antidepressant, Lu AA21004. Drug Metab Dispos. 2012;40(7):1357-1365.

16. Jain R, Mahableshwarkar AR, Jacobsen PL, Chen Y, Thase ME. A randomized, double-blind, placebo-controlled 6-wk trial of the efficacy and tolerability of $5 \mathrm{mg}$ vortioxetine in adults with major depressive disorder. Int J Neuropsychopharmacol. 2013;16(2):313-321.

17. Baldwin DS, Loft H, Dragheim M. A randomised, double-blind, placebo controlled, duloxetine-referenced, fixed-dose study of three dosages of Lu AA21004 in acute treatment of major depressive disorder (MDD). Eur Neuropsychopharmacol. 2012;22(7):482-491.

18. Mahableshwarkar AR, Jacobsen PL, Serenko M, Chen Y, Trivedi MH. A duloxetine-referenced, fixed dose study comparing efficacy and safety of 2 vortioxetine doses in the acute treatment of adult MDD patients. Poster Presented at: American Psychiatry Association Annual Meeting; May 18-22, 2013; San Francisco, CA.

19. McIntyre RS, Lophaven S, Olsen CK. Randomized, double-blind, placebo-controlled study of the efficacy of vortioxetineon cognitive function in adult patients with major depressive disorder (MDD). Poster presented at: 52nd Annual Meeting of the American College of Neuropsychopharmacology (ACNP); December 8-12, 2013; Hollywood, FL.

20. Häggström L, Nielsen RZ, Poulsen L, Danchenko N. A randomised, double blind, active controlled study of vortioxetine (10-20 mg/day) versus agomelatine $(25-50 \mathrm{mg} /$ day $)$ in adults with Major Depressive Disorder with inadequate response to antidepressant treatment. Poster presented at: 26th Congress of the European College of Neuropsychopharmacology (ECNP); October 5-9, 2013; Barcelona, Spain.

21. Jacobsen PL, Mahableshwarkar AR, Serenko M, Chan S, Trivedi MH. A randomized, double-blind, placebo-controlled study of the efficacy and safety of vortioxetine $10 \mathrm{mg}$ and $20 \mathrm{mg}$ in adults with Major Depressive Disorder. Poster presented at: American Psychiatry Association Annual Meeting; May 18-22, 2013; San Francisco, CA.

22. Mahableshwarkar AR, Jacobsen PL, Chen Y. A randomized, doubleblind trial of $2.5 \mathrm{mg}$ and $5 \mathrm{mg}$ vortioxetine (Lu AA21004) versus placebo for 8 weeks in adults with major depressive disorder. Curr Med Res Opin. 2013;29(3):217-226.

23. Mahableshwarkar AR, Jacobsen PL, Serenko M, Chen Y, Trivedi MH. A randomized, double blind, parallel, placebo-controlled, fixed-dose study comparing the efficacy and safety of 2 doses of vortioxetine (LU AA21004) in acute treatment of adults with major depressive disorder. Poster presented at: American Psychiatry Association Annual Meeting; May 18-22, 2013; San Francisco, CA.
24. Alvarez E, Perez V, Dragheim M, Loft H, Artigas F. A doubleblind, randomized, placebo-controlled, active reference study of $\mathrm{Lu}$ AA21004 in patients with major depressive disorder. Int J Neuropsychopharmacol. 2012;15(5):589-600.

25. Henigsberg N, Mahableshwarkar AR, Jacobsen P, Chen Y, Thase ME. A randomized, double-blind, placebo-controlled 8-week trial of the efficacy and tolerability of multiple doses of Lu AA21004 in adults with major depressive disorder. J Clin Psychiatry. 2012;73(7):953-959.

26. Katona C, Hansen T, Olsen CK. A randomized, double-blind, placebocontrolled, duloxetine-referenced, fixed-dose study comparing the efficacy and safety of Lu AA21004 in elderly patients with major depressive disorder. Int Clin Psychopharmacol. 2012;27(4):215-223.

27. Boulenger JP, Loft $\mathrm{H}$, Olsen CK. Efficacy and safety of vortioxetine ( $\mathrm{Lu}$ AA21004), 15 and $20 \mathrm{mg}$ /day: a randomized, double-blind, placebocontrolled, duloxetine-referenced study in the acute treatment of adult patients with major depressive disorder. Int Clin Psychopharmacol. 2014;29(3):138-149.

28. Boulenger JP, Loft H, Florea I. A randomized clinical study of Lu AA21004 in the prevention of relapse in patients with major depressive disorder. J Psychopharmacol. 2012;26(11):1408-1416.

29. Baldwin DS, Hansen T, Florea I. Vortioxetine (Lu AA21004) in the long-term open-label treatment of major depressive disorder. Curr Med Res Opin. 2012;28(10):1717-1724.

30. Millan MJ, Gobert A, Lejeune F, et al. The novel melatonin agonist agomelatine (S20098) is an antagonist at 5-hydroxytryptamine2C receptors, blockade of which enhances the activity of frontocortical dopaminergic and adrenergic pathways. J Pharmacol Exp Ther. 2003; 306(3):954-964.

31. Serretti A, Chiesa A. Treatment-emergent sexual dysfunction related to antidepressants: a meta-analysis. J Clin Psychopharmacol. 2009; 29(3):259-266.

32. Nicolosi A, Laumann EO, Glasser DB, Moreira ED Jr, Paik A, Gingell C; Global Study of Sexual Attitudes and Behaviors Investigators' Group. Sexual behavior and sexual dysfunctions after age 40: the global study of sexual attitudes and behaviors. Urology. 2004;64(5): 991-997.

33. Amstislavskaya TG, Popova NK. The roles of different types of serotonin receptors in activation of the hypophyseal-testicular complex induced in mice by the presence of a female. Neurosci Behav Physiol. 2004;34(8):833-837.

34. Khin NA, Chen YF, Yang Y, Yang P, Laughren TP. Exploratory analyses of efficacy data from major depressive disorder trials submitted to the US Food and Drug Administration in support of new drug applications. J Clin Psychiatry. 2011;72(4):464-472.

35. Mundt JC, Greist JH, Jefferson JW, et al. Is it easier to find what you are looking for if you think you know what it looks like? J Clin Psychopharmacol. 2007;27(2):121-125.

36. Stewart-Williams S, Podd J. The placebo effect: dissolving the expectancy versus conditioning debate. Psychol Bull. 2004;130(2):324-340.

37. Citrome L. Vortioxetine for major depressive disorder: a systematic review of the efficacy and safety profile for this newly approved antidepressant - what is the number needed to treat, number needed to harm and likelihood to be helped or harmed? Int J Clin Pract. 2014;68(1): $60-82$.
Neuropsychiatric Disease and Treatment

\section{Publish your work in this journal}

Neuropsychiatric Disease and Treatment is an international, peerreviewed journal of clinical therapeutics and pharmacology focusing on concise rapid reporting of clinical or pre-clinical studies on a range of neuropsychiatric and neurological disorders. This journa is indexed on PubMed Central, the 'PsycINFO' database and CAS,

\section{Dovepress}

and is the official journal of The International Neuropsychiatric Association (INA). The manuscript management system is completely online and includes a very quick and fair peer-review system, which is all easy to use. Visit http://www.dovepress.com/testimonials.php to read real quotes from published authors. 